\title{
El derecho de participación política de las personas con discapacidad: el caso de España tras más de una década de vigencia de la Convención internacional sobre los derechos de las personas con discapacidad
}

\section{The right to political participation of people with disabilities: the situation in Spain after more than a decade of the Convention on the Rights of Persons with Disabilities coming into effect.}

LEONOR LIDÓN HERAS

Universidad Católica de Valencia, España

RECEPCIÓN: 20/09/2017 • ACEPTACIÓN: 30/10/2017

RESUMEN: La vulneración del derecho de voto en España presenta una doble dimensión, pues se puede denegar su titularidad y/o su ejercicio.

El presente artículo presenta un análisis fáctico, legal y jurisprudencial de la realidad del derecho al voto de las personas con discapacidad en España. Para ello, toma como punto de partida el contenido esencial del derecho conforme al artículo 29 de la Convención Internacional sobre los Derechos de las Personas con Discapacidad, y a lo establecido por su Comité en sus observaciones generales y jurisprudencia.

Las conclusiones muestran que la restricción de este derecho es un menoscabo a la libertad y a la igualdad y no discriminación, pues, conforme al modelo de derechos humanos de la Convención, no está permitida ninguna restricción.

ABSTRACT: The violation of the right to vote in Spain has a double dimension since people with disabilities may be denied the right to register as voters and the right to vote.

This article presents a factual, legal and jurisprudential analysis of the situation regarding the right to vote of people with disabilities in Spain. The analysistakes as its starting points the essential content of the right established by article 
29 of the International Convention on the Rights of Persons with Disabilities, and the conditions established by its Committee in its general observations and jurisprudence.

The conclusions show that the restriction of this right implies a violation of freedom, equality and non-discrimination, which, according to the human rights model of the Convention, may not suffer any restriction.

PALABRAS CLAVE: Derecho de voto - Discapacidad - Derechos Humanos España, Comité derechos de las personas con discapacidad.

KEY WORDS: Right to vote - disability - human rights - Spain- Committee on the Rights of Persons with Disabilities.

\section{Introducción}

La Convención sobre los Derechos de las Personas con Discapacidad (en adelante Convención o CDPD), primer texto de derechos humanos del siglo XXI, fue aprobada por la Asamblea General de Naciones Unidas el 13 de diciembre de 2006.

Para comprender la necesidad de un tratado específico en materia de discapacidad hay que tener presente por un lado la insuficiencia de los demás tratados para proteger los derechos de las personas con discapacidad y por otro, la transformación que, desde los años 70, se había ido plasmando en la forma de percibir la discapacidad. Esta evolución transitó desde entender la exclusión de las personas con discapacidad (social y jurídica) como algo natural y por tanto como un problema individual derivado de su discapacidad, hasta asimilar que son las sociedades las que generan exclusión o inclusión, y que es la misma sociedad la que debe definirse desde la igualdad, la no discriminación y la autonomía. Sin embargo, estamos ante un proceso lento, inconcluso y asimétrico donde todas las formas de entender a la discapacidad aún conviven.

La CDPD es un tratado de derechos humanos orientado a que las personas con discapacidad puedan, en igualdad de condiciones, disfrutar de sus derechos humanos, derechos que son iguales a los de los demás pero que requieren de mecanismos de protección y garantía específicos debido a las deficiencias, pero también, en gran medida, a las desigualdades estructurales.

Por ello la Convención era necesaria y porque además tiene como propósito poner fin al pertinaz olvido y abandono de los derechos humanos de las personas 
con discapacidad, entre los que está el derecho de participación política reconocido en el su artículo 29.

Este reconocimiento es un hito, pues es uno de los muchos derechos que ha sido vulnerado a las personas con discapacidad.

Antes de ahondar en su contenido y obligaciones para los Estados Parte, es necesario conocer el impacto y el significado que implica la CDPD para el estándar internacional de derechos humanos y para ello el primer paso es comprender cómo define la CDPD la discapacidad, que lo hace como la interacción entre deficiencia y barrera.

Figura 1.

Definición de la Discapacidad de conformidad a la Convención Internacional de los Derechos de las Personas con Discapacidad
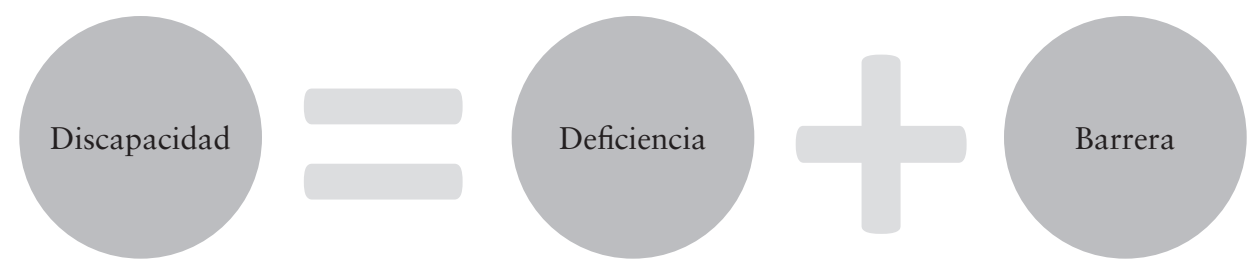

Al definir la discapacidad como una interacción, nos permite afirmar que la «discapacidad» no es un atributo de la persona ${ }^{1}$. En ella se inserta la dimensión biológica (la deficiencia) propia del individuo y la dimensión social (la barrera), que es de la sociedad. Con esta definición se rompe la relación causa-efecto que justificaba la exclusión de las personas con discapacidad en ellas y no en la sociedad ${ }^{2}, y$ sitúa la atención y por tanto la responsabilidad en la sociedad.

Este cambio de enfoque es revolucionario, pues identifica que la clave de la inclusión está en la sociedad, sin embargo, basta mirar nuestras sociedades y reflexionar sobre cómo las graves carencias en accesibilidad ${ }^{3}$ y de diseño

1. OMS y Banco Mundial (2011), p. 7.

2. Es el denominado modelo médico de la discapacidad, que entendía que si una persona con discapacidad no podía acceder a un bien o servicio era debido, precisamente a su discapacidad. Así, si una persona en silla no podía entrar en un edificio con escaleras, la «culpa» era de la persona y de su discapacidad. Este enfoque es tremendamente individualista y no atiende a las causas estructurales de la desigualdad.

3. El Real Decreto Legislativo 1/2013, de 29 de noviembre, por el que se aprueba el Texto Refundido de la Ley General de derechos de las personas con discapacidad y de su inclusión social, 
universal ${ }^{4}$ definen un modelo de convivencia que limita y excepciona los derechos de ciudadanía de las personas con discapacidad.

Por ello, puede afirmarse que la Convención es el marco de derechos humanos que trata de dar respuesta a la realidad de las personas con discapacidad, que está marcada por la exclusión y la discriminación a través de las barreras mentales que se expresan en barreras jurídicas, relacionales, y físicas y a la comunicación. Debe entenderse dentro del proceso emancipatorio de las personas con discapacidad, y de la evolución de los propios derechos humanos en sede de Naciones Unidas. Expresa, a través de la relectura de los derechos humanos, la distancia entre realidad y norma, especialmente a través de los derechos que refuerza y a la relevancia que se concede a la igualdad y a la autonomía. En definitiva, crea un marco para entender y aplicar el binomio derechos humanos-discapacidad que se sustenta en una premisa básica: misma condición de ser humano, mismos derechos, mismo entorno, todo ello desde la igualdad material.

Precisamente una de sus grandes aportaciones es que las barreras permiten ser denunciadas como violaciones de los derechos humanos. Otro avance esencial, frente a textos anteriores del soft y hard law de Naciones Unidas, es que los derechos que enuncia y contiene no admiten excepciones ni limitaciones.

Para reforzar este planteamiento, la CDPD no solo define derechos, sino que crea una estructura de interpretación que entrelaza principios, obligaciones y derechos.

El primer marco de interpretación es el preámbulo que muestra ya la singularidad del texto, pues es único en riqueza y extensión de sus preceptos comparado con los demás textos del sistema internacional de tratados. Su contenido conjuga

la define en su artículo 2: «Es la condición que deben cumplir los entornos, procesos, bienes, productos y servicios, así como los objetos, instrumentos, herramientas y dispositivos, para ser comprensibles, utilizables y practicables por todas las personas en condiciones de seguridad y comodidad y de la forma más autónoma y natural posible. Presupone la estrategia de 'diseño universal o diseño para todas las personas', y se entiende sin perjuicio de los ajustes razonables que deban adoptarse».

4. El Real Decreto Legislativo 1/2013, de 29 de noviembre, por el que se aprueba el Texto Refundido de la Ley General de derechos de las personas con discapacidad y de su inclusión social, la define en su artículo 2: «Diseño universal o diseño para todas las personas: es la actividad por la que se conciben o proyectan desde el origen, y siempre que ello sea posible, entornos, procesos, bienes, productos, servicios, objetos, instrumentos, programas, dispositivos o herramientas, de tal forma que puedan ser utilizados por todas las personas, en la mayor extensión posible, sin necesidad de adaptación ni diseño especializado. El 'diseño universal o diseño para todas las personas‘ no excluirá los productos de apoyo para grupos particulares de personas con discapacidad, cuando lo necesiten». 
la realidad de la vulneración de derechos con la variabilidad y especificidad de la discapacidad y con los principios que define para la inclusión.

Estos principios del preámbulo se incorporan a la parte dispositiva de la Convención a través de su artículo 3, que contiene diferentes principios clásicos de los derechos humanos como dignidad, no discriminación o igualdad de oportunidades, así como principios específicos como la accesibilidad. A los que se añaden otros que quieren revertir situaciones endémicas de vulneración de derechos y que afirman: la autonomía individual, incluida la libertad de tomar las propias decisiones y la independencia de las personas; la participación e inclusión plenas y efectivas en la sociedad; y el respeto por la diferencia y la aceptación de las personas con discapacidad como parte de la diversidad y la condición humanas.

La igualdad tiene un contenido singular que se define en tres niveles. El primer nivel describe un marco genérico que afirma la igualdad ante la ley y el derecho a beneficiarse de la misma sin discriminación. El segundo nivel, refuerza la prohibición de discriminación por motivo de discapacidad unido a la protección legal igual y efectiva contra la discriminación. Y, por último, el tercer nivel se asienta en acciones concretas e individualizadas, a través de la adopción de todas las medidas pertinentes que aseguren la realización de ajustes razonables.

Dentro del marco transversal de la igualdad destacan los mecanismos de equiparación, que operan igualando oportunidades mediante la creación de situaciones de partida equiparables, en las que las desigualdades son prevenidas o eliminadas, a través de la accesibilidad o de los ajustes razonables.

Este marco de principios aporta contenido exigible a las obligaciones de los Estados Parte definidas en el cumplimiento de la Convención y que están incluidas de forma profusa en su artículo 4.

Es en este contexto donde debe situarse el derecho a la participación política, como un derecho pleno, sin excepciones en el que se deben reconocer el derecho, así como los mecanismos de equiparación que sean necesarios para su pleno ejercicio.

\section{El derecho al voto de conformidad con la CDPD}

\subsection{Configuración del derecho de participación política en la CDPD}

El análisis de la configuración de este derecho debe hacerse desde una triple perspectiva: lo contenido en el propio artículo 29 de la CDPD, las observaciones generales del Comité CDPD que incluyen referencias al mismo, y la jurisprudencia del propio Comité. 


\subsubsection{Artículo 29 de la CDPD}

Una lectura crítica de la Convención permite conocer las barreras que enfrentan las personas con discapacidad en el ejercicio de sus derechos, pues en su redacción se identifican definiendo así obligaciones concretas a los Estados para su eliminación. El artículo 29 no escapa a esta orientación, por cuanto su extenso contenido se orienta, precisamente, a garantizar el propio derecho que proclama:

Artículo 29. Participación en la vida política y pública

Los Estados Partes garantizarán a las personas con discapacidad los derechos políticos y la posibilidad de gozar de ellos en igualdad de condiciones con las demás y se comprometerán a:

a) Asegurar que las personas con discapacidad puedan participar plena y efectivamente en la vida política y pública en igualdad de condiciones con las demás, directamente o a través de representantes libremente elegidos, incluidos el derecho y la posibilidad de las personas con discapacidad a votar y ser elegidas, entre otras formas mediante:

i) La garantía de que los procedimientos, instalaciones y materiales electorales sean adecuados, accesibles y fáciles de entender y utilizar;

ii) La protección del derecho de las personas con discapacidad a emitir su voto en secreto en elecciones y referéndum públicos sin intimidación, y a presentarse efectivamente como candidatas en las elecciones, ejercer cargos $y$ desempeñar cualquier función pública a todos los niveles de gobierno, facilitando el uso de nuevas tecnologías y tecnologías de apoyo cuando proceda;

iii) La garantía de la libre expresión de la voluntad de las personas con discapacidad como electores y a este fin, cuando sea necesario y a petición de ellas, permitir que una persona de su elección les preste asistencia para votar;

b) Promover activamente un entorno en el que las personas con discapacidad puedan participar plena y efectivamente en la dirección de los asuntos públicos, sin discriminación y en igualdad de condiciones con las demás.

Por tanto, desde la igualdad, la no discriminación y la autonomía reconoce:

a) El derecho de sufragio activo y pasivo, tanto en titularidad como en ejercicio.

b) El derecho de participación, tanto en titularidad como en ejercicio. 


\subsubsection{Observaciones Generales del Comité CDPD que hacen referencia al derecho de participación política}

Otro aspecto esencial para conocer el alcance de los derechos reconocidos en las diferentes convenciones internacionales de Naciones Unidas es atender a las observaciones generales de sus respectivos comités que desarrollan sus criterios sobre el contenido de las obligaciones contraídas por los Estados Partes ${ }^{5}$.

El Comité CDPD, en su primera observación general relativa a la capacidad jurídica, trata extensamente el derecho de participación política, y estableció que

8. El artículo 12 de la Convención afirma que todas las personas con discapacidad tienen plena capacidad jurídica. Esa capacidad ha sido negada de forma discriminatoria a muchos grupos a lo largo de la historia, como las mujeres (sobre todo al contraer matrimonio) y las minorías étnicas. Sin embargo, las personas con discapacidad siguen siendo el grupo al que más comúnmente se le niega la capacidad jurídica en los ordenamientos jurídicos de todo el mundo. El derecho al igual reconocimiento como persona ante la ley entraña que la capacidad jurídica es un atributo universal inherente a todas las personas en razón de su condición humana y debe mantenerse para las personas con discapacidad en igualdad de condiciones con las demás. La capacidad jurídica es indispensable para el ejercicio de los derechos civiles, politicos, económicos, sociales y culturales, y adquiere una importancia especial para las personas con discapacidad cuando tienen que tomar decisiones fundamentales con respecto a su salud, su educación y su trabajo. En muchos casos, la negación de la capacidad jurídica a las personas con discapacidad ha hecho que se vean privadas de muchos derechos fundamentales, como el derecho de voto, el derecho a casarse y fundar una familia, los derechos reproductivos, la patria potestad, el derecho a otorgar su consentimiento para las relaciones intimas y el tratamiento médico y el derecho a la libertad.

29. Un régimen de apoyo para la adopción de decisiones comprende diversas opciones de apoyo que dan primacía a la voluntad y las preferencias de la persona y respetan las normas de derechos humanos (...) f) El apoyo en la

5. Reforma de las Naciones Unidas: medidas y propuestas, Doc. A/66/860, 26 de junio de 2012. p. 72.

6. El subrayado de los aspectos esenciales concernientes al derecho de voto es propio.COMMITTEE ON THE RIGHTS OF PERSONS WITH DISABILITIES $(2014$, a) 
adopción de decisiones no debe utilizarse como justificación para limitar otros derechos fundamentales de las personas con discapacidad, especialmente el derecho de voto, el derecho a contraer matrimonio, o a establecer una unión civil, y a fundar una familia, los derechos reproductivos, la patria potestad, el derecho a otorgar su consentimiento para las relaciones intimas y el tratamiento médico y el derecho a la libertad.

48. La negación o la limitación de la capacidad jurídica han sido utilizadas para negar la participación politica, especialmente el derecho de voto, a determinadas personas con discapacidad. Para hacer plenamente efectivo el reconocimiento de la capacidad jurídica en igualdad de condiciones en todos los aspectos de la vida, es importante que se reconozca la capacidad jurídica de las personas con discapacidad en la vida pública y política (art. 29).

Esto significa que la capacidad de adoptar decisiones no puede justificar que se excluya a las personas con discapacidad del ejercicio de los derechos politicos, incluidos el derecho de voto, el derecho a presentarse como candidatas en las elecciones y el derecho a ser miembros de un jurado.

49. Los Estados partes tienen la obligación de proteger y promover el derecho de las personas con discapacidad de acceder al apoyo de su elección para emitir su voto en secreto y participar sin discriminación en todas las elecciones y referendos. El Comité recomienda además a los Estados partes que garanticen el derecho de las personas con discapacidad a presentarse como candidatas en las elecciones, ejercer efectivamente cargos y desempeñar cualquier función pública en cualquier nivel de gobierno, con ajustes razonables y apoyo, cuando lo deseen, en el ejercicio de su capacidad jurídica.

Por tanto, el Comité CDPD afirma sin lugar a dudas o interpretaciones que no se puede negar el derecho al voto a las personas con discapacidad, con independencia de que esta pueda necesitar mecanismos de apoyo a su capacidad jurídica.

El Comité CDPD en el resto de observaciones generales también ha tratado de forma transversal este derecho. Así, en la observación general n ${ }^{\circ} 3$ relativa a las mujeres y niñas con discapacidad aborda entre otros su discriminación múltiple e interseccional en el acceso a derechos, denuncia su menor acceso a la participación política y su consiguiente subrepresentación en los procesos de decisión política ${ }^{7}$.

7. Committee on the Rights of Persons with disabilities $(2016$, a) par. 10 y 60. 
Por ello, entre las líneas de acción que marca el Comité se encuentra tanto el empoderamiento de las mujeres niñas como la modificación de toda norma o política que restrinja su plena participación en la vida política ${ }^{8}$.

En la observación general dedicada al derecho a la educación inclusiva, recuerda la relación que existe entre educación inclusiva y plena participación en la vida política y pública, por ello insta a que en los curricula educativos existan materias sobre ciudadanía y se promueva la participación de los estudiantes a través de organizaciones en las que tengan cabida las personas con discapacidad ${ }^{9}$.

El derecho de participación política también está íntimamente relacionado con el derecho a vivir en comunidad. En este sentido, el Comité recuerda que los servicios de apoyo deben incluir y favorecer la esfera de la participación política, y que, las personas con discapacidad deben poder influir en sus condiciones de vida a través de su participación política ${ }^{10}$.

Por otra parte, debe tenerse presente la observación $n^{\circ} 2$ del Comité CDPD en aquellos aspectos que afectan al derecho de participación política desde el punto de vista de la accesibilidad ${ }^{11}$ :

a) Afirma que la accesibilidad es una cuestión que asegurar, proteger y respetar, y fija como objetivo la accesibilidad plena.

b) Vincula accesibilidad e igualdad y no discriminación, por lo que la obligación de asegurarla en el entorno físico, los transportes, la información y la comunicación y los servicios abiertos al público debe asumirse desde el principio de igualdad y no discriminación, por lo que la denegación de acceso en estos ámbitos constituye discriminación prohibida por el art. 5 de la Convención.

c) Recuerda que es una condición previa para la participación plena en sociedad y debe considerarse como una reafirmación del derecho de acceso desde la propia especificidad de las personas con discapacidad.

d) Establece que las medidas de austeridad no pueden ser un argumento para demorar la implementación gradual de la accesibilidad, pues esta obligación es de aplicación inmediata.

\footnotetext{
8. CommitTeE On the RightS OF PeRsons with Disabilities (2016, a) par. 21, 23 y 62 a) i)

9. Committee on the Rights of Persons with disabilities $(2016$, b) par. 55.

10. Committee on the RightS of Persons With disabilities (2016, c) par. 29 y 94.

11. Committee on the Rights of Persons with disabilities $(2014$, b) par. $1 ; 4 ; 14 ; 24 ; 34$.
} 


\subsubsection{Jurisprudencia del Comité en relación con el derecho de participación política}

El Comité CDPD ha tenido oportunidad de pronunciarse sobre el derecho al voto de las personas con discapacidad. En la Comunicación N ${ }^{\circ}$ 4/2011 presentada contra Hungría, el Comité debía decidir si la normativa húngara era discriminatoria por razón de discapacidad y si se garantizaban o no los derechos políticos de las personas con discapacidad, incluido el derecho de voto, en pie de igualdad con los demás ciudadanos.

En el momento de producirse la denuncia, la constitución húngara de 1949 establecía la exclusión directa del derecho de voto de toda persona sujeta a tutela parcial o total. Posteriormente en 2012, y antes de la resolución del proceso se produjo una reforma constitucional que, a diferencia del sistema automático previo de exclusión, establecía que la decisión sobre la denegación del derecho al voto la debe tomar de forma individualizada cada juez atendiendo a las circunstancias de la persona, y con base en los dictámenes de los psiquiatras forenses. Conforme a la reforma constitucional de 2012, la exclusión deja de ser directa, pero se mantiene la denegación individualizada mediante decisión judicial. El Comité, en su decisión final y tras valorar y analizar el contenido material del derecho al voto de conformidad a la CDPD y las alegaciones de las partes, estableció que ${ }^{12}$ :

a) La obligación de los Estados Partes es asegurar la plena y efectiva participación en la vida política en igualdad de condiciones, sin que quepan restricciones ni excepciones con respecto a ningún grupo de personas con discapacidad, de forma que, cualquier exclusión sobre esta base es discriminatoria por motivo de discapacidad. Por ello, el artículo XXIII, párrafo 6, de la Ley fundamental, que permite a los tribunales la privación a las personas con discapacidad intelectual del derecho a votar y a ser elegidas, contraviene el artículo 29 de la Convención, al igual que el artículo 26, párrafo 2, de las disposiciones transitorias de la Ley fundamental.

b) Los Estados Partes deben, con relación a la capacidad jurídica, reconocerla y protegerla en igualdad de condiciones, lo que implica la adopción de medidas que garanticen su ejercicio. Por ello, restringir el derecho al voto sobre la base de una discapacidad intelectual percibida o real es un incumplimiento de las obligaciones del artículo 29 de la Convención, leído por separado y junto con el artículo 12 de la Convención.

12. Comité Sobre los Derechos de las personas Con DisCapacidad (2011, a) par. 9.4-9.7. 
c) El Comité considera discriminatoria la evaluación de la capacidad de las personas y no es defendible la legitimidad de esta medida, y tampoco lo es bajo el objetivo de preservar la integridad del sistema político del Estado Parte, pues este debe adaptar y hacer accesibles sus procedimientos electorales, así como facilitar asistencia a las personas con discapacidad que lo soliciten.

d) Por todo ello estima que el Estado Parte (Hungría) ha incumplido las obligaciones que le incumben con relación al artículo 29, y entre otros le insta a considerar la derogación de la mencionada ley y a promulgar legislación que reconozca sin ninguna evaluación de la capacidad el derecho de voto de las personas con discapacidad sin exclusión alguna y que prevea un sistema de asistencia adecuado que contemplen ajustes razonables.

\section{El derecho de participación política en España}

Una vez definido el contenido del derecho de participación política de acuerdo con la Convención y a la interpretación del Comité CDPD, como pleno, sin excepciones y garantizado por los principios de igualdad, no discriminación y autonomía, procede el análisis del caso de España ${ }^{13}$.

En este apartado analiza la aplicabilidad de la Convención de conformidad con la normativa española, las consideraciones que el Comité CDPD hizo en sus observaciones finales al examen presentado por el estado español, así como la normativa y jurisprudencia española al respecto, y, por último, una mirada sobre la realidad desde dicha normativa.

\subsection{La Convención como normativa interna española: recepción, aplicación e invocación del Tratado}

La CDPD, de conformidad con la Constitución Española forma parte del ordenamiento jurídico españo ${ }^{14} \mathrm{y}$, además, es referente de interpretación de los derechos fundamentales ${ }^{15}$.

13. La Convención, fue firmada por España el 30 de marzo de 2007, ratificada el 23 de noviembre de 2007, y publicada en el BOE de 21 de abril de 2008. Su entrada en vigor se produjo, tras alcanzar X ratificaciones, el 3 de mayo de 2008.

14. Art. 96. 1 CE: "Los tratados internacionales válidamente celebrados, una vez publicados oficialmente en España, formarán parte del ordenamiento interno. Sus disposiciones solo podrán ser derogadas, modificadas o suspendidas en la forma prevista en los propios tratados o de acuerdo con las normas generales del Derecho internacional”.

15. Art. 10.2 CE: "Las normas relativas a los derechos fundamentales y a las libertades que la 
Por su parte, la Ley 25/2014, de 27 de noviembre, de Tratados y otros Acuerdos Internacionales refuerza dicha obligatoriedad, pues afirma su eficacia desde su entrada en vigor; su aplicabilidad directa por todas las entidades territoriales y su prevalencia en caso de conflicto frente a cualquier norma del ordenamiento interno, salvo las de rango constitucional; y, en relación a la interpretación de los mismos, manifiesta que se tendrá en cuenta toda la normativa pertinente de la organización internacional de la que emanan ${ }^{16}$.

Es por tanto un tratado internacional directamente invocable y aplicable en todos los niveles territoriales, como marco de derechos y como marco de interpretación de los derechos fundamentales.

2.2 Observaciones finales del comité sobre los derechos de las personas con discapacidad al informe de España

En el año 2011, tres años después de la entrada en vigor en España de la CDPD, el Comité elaboró sus observaciones finales ${ }^{17}$ al examen presentado por España. En ellas, el Comité recomendó una profunda revisión legislativa tendiente a asegurar que todas las personas con discapacidad, independientemente de su deficiencia, de su condición jurídica o de su lugar de residencia, tuvieran derecho a votar y a participar en la vida pública en pie de igualdad con los demás. Por ello, instó a la modificación del artículo 3 de la Ley Orgánica 5/1985, del Régimen Electoral General, y exhortó también a que todas las personas con discapacidad que fueran elegidas para desempeñar un cargo público dispusieran de toda la asistencia necesaria, incluso asistentes personales ${ }^{18}$ :

47. Preocupa al Comité que se pueda restringir el derecho al voto de las personas con discapacidad intelectual o psicosocial si la persona interesada ha sido privada de su capacidad jurídica o ha sido internada en una institución. Le inquieta además que la privación de ese derecho parezca ser la regla y no la excepción. El Comité lamenta la falta de información sobre el rigor de las normas en materia de prueba, sobre los motivos requeridos y sobre los criterios aplicados por los jueces para privar a las personas de su derecho

Constitución reconoce se interpretarán de conformidad con la Declaración Universal de Derechos Humanos y los tratados y acuerdos internacionales sobre las mismas materias ratificados por España”.

16. Ley 25/2014, de 27 de noviembre, de Tratados y otros Acuerdos Internacionales art. 28.2; art. 30; art. 3; art. 35.2

17. COMité sobre los Derechos de las PERSONAS CON Discapacidad (2011, b).

18. COMITÉ SObRe LOS DERECHOS DE LAS PERSONAS CON DISCAPACIDAD $(2011$, b). 
de voto. El Comité observa con preocupación el número de personas con discapacidad a las que se ha denegado el derecho de voto.

48. El Comité recomienda que se revise toda la legislación pertinente para que todas las personas con discapacidad, independientemente de su deficiencia, de su condición jurídica o de su lugar de residencia, tengan derecho a votar y a participar en la vida pública en pie de igualdad con los demás. El Comité pide al Estado parte que modifique el artículo 3 de la Ley orgánica $N^{\circ} 5 / 1985$, que autoriza a los jueces a denegar el derecho de voto en virtud de decisiones adoptadas en cada caso particular. La modificación debe hacer que todas las personas con discapacidad tengan derecho a votar. Además, se recomienda que todas las personas con discapacidad que sean elegidas para desempeñar un cargo público dispongan de toda la asistencia necesaria, incluso asistentes personales.

\subsection{Legislación sobre el derecho de participación política en España}

La descripción del sistema legal incluye el derecho de voto desde el punto de vista de su titularidad y su ejercicio.

\subsubsection{El derecho de voto}

Es bien sabido que el derecho al voto nace con la abolición de los estados absolutos y el advenimiento de los estados liberales de derecho en los albores del siglo XIX. Si bien la referencia al mismo se hace bajo la denominación de sufragio universal, ello no debe llamarnos a engaño, pues no fue ni es universal su reconocimiento, de hecho, parte de la lucha de los derechos humanos has sido, precisamente, la inclusión en el mismo de grupos y colectivos que quedaron excluidos. El derecho al voto de las mujeres, reclamado por las sufragistas, es un claro ejemplo de esta realidad. Y en el siglo XXI aún encontramos restricciones de las que el estado español participa.

La regulación del derecho de sufragio se encuentra en la Ley Orgánica 5/1985, de 19 de junio, del Régimen Electoral General (en adelante LOREG), en su artículo tercero apartado 1 dispone que carecen de sufragio:

a) Los condenados por sentencia judicial firme a la pena principal o accesoria de privación del derecho de sufragio durante el tiempo de su cumplimiento.

b) Los declarados incapaces en virtud de sentencia judicial firme, siempre que la misma declare expresamente la incapacidad para el ejercicio del derecho de sufragio. 
c) Los internados en un hospital psiquiátrico con autorización judicial, durante el periodo que dure su internamiento siempre que en la autorización el juez declare expresamente la incapacidad para el ejercicio del derecho de sufragio.

De acuerdo con los apartados b) y c) la norma exige que los Jueces o Tribunales que entiendan de los procedimientos de modificación de la capacidad o internamiento psiquiátrico se pronuncien expresamente sobre la incapacidad para el ejercicio del sufragio. En el supuesto de que esta sea apreciada, lo comunicaran al Registro Civil para que se proceda a la anotación correspondiente. Debe tenerse presente que el texto de la norma habla directamente de incapacidad y no de capacidad, de forma que centrada en aquella obvia las formas de apoyo a la capacidad o cualesquiera otras fórmulas que pudieran ser necesarias ${ }^{19}$.

En la medida que esta limitación afecta a aquellas personas cuya capacidad judicial pueda verse modificada y a personas que puedan ser internadas, dentro del ámbito de las discapacidades, nos sitúa dentro de las de tipo intelectual y/o psicosocial.

En un intento de adaptación a la CDPD, en 2010, la Fiscalía emitió una Instrucción marcando las directrices a seguir por los fiscales en los procesos de modificación de la capacidad. En ella plantea la privación del derecho de voto como excepcional y debe repercutir en el exclusivo interés de la persona cuya capacidad ha sido modificada judicialmente ${ }^{20}$.

\subsubsection{Normativa sobre la participación en la vida política de las personas con discapacidad}

Los tres textos de referencia sobre la participación política de las personas con discapacidad son el Real Decreto Legislativo 1/2013, de 29 de noviembre, por el que se aprueba el Texto Refundido de la Ley General de derechos de las personas con discapacidad y de su inclusión social (LGDPCD), el Real Decreto 422/2011, de 25 de marzo, por el que se aprueba el Reglamento sobre las condiciones básicas para la participación de las personas con discapacidad en la vida política y en los procesos electorales y el Real Decreto 1612/2007, por el que se regula un procedimiento de voto accesible.

19. En España no se ha producido tampoco la reforma legal que exige el artículo 12 de la Convención relativo a la capacidad jurídica.

20. Fiscalía General del ESTADO (2010). 
Entre los derechos que regula la LGDPCD está el de participación en la vida política y pública en igualdad de condiciones que los demás ciudadanos conforme a la normativa en vigor. Para garantizar este derecho, las administraciones públicas pondrán a su disposición los medios y recursos que precisen ${ }^{21}$. Por otra parte, esta ley como norma marco define la igualdad y no discriminación y la obligación de proveer ajustes razonables que aplica a todos los ámbitos contenidos en la misma ${ }^{22}$.

Por su parte, el Real Decreto 422/2011, de 25 de marzo, por el que se aprueba el Reglamento sobre las condiciones básicas para la participación de las personas con discapacidad en la vida política y en los procesos electorales, destaca en su regulación los siguientes aspectos:

a) Los espacios autorizados que los Ayuntamientos reserven para los actos gratuitos de campaña deben ser accesibles. Los candidatos, partidos políticos, coaliciones y las agrupaciones de electores que concurran a un proceso electoral procurarán que los actos de campaña electoral sean accesibles.

b) Los soportes de espacios gratuitos de propaganda electoral tratarán de atender las necesidades específicas de accesibilidad de las personas con discapacidad; los candidatos, partidos políticos, federaciones, coaliciones y las agrupaciones de electores procurarán que la propaganda electoral sea accesible.

c) Las campañas institucionales en soporte audiovisual que informen sobre las elecciones y el derecho al voto deben estar subtituladas, audio descritas, y en lengua de signos. Además, los servicios de atención telefónica que se pongan en marcha también deberán ser accesibles, especialmente para las personas sordas, con discapacidad auditiva y sordociegas.

d) Prevé un sistema de transporte para aquellas personas con dificultades de movilidad cuando no haya transporte accesible al lugar de la votación.

e) Establece que los lugares y recintos para votar deben ser accesibles.

f) Las personas sordas o con discapacidad auditiva usuarias de lengua de signos que hayan sido designadas miembro de una Mesa podrán contar con un intérprete de lengua de signos.

21. Real Decreto Legislativo 1/2013, de 29 de noviembre, por el que se aprueba el Texto Refundido de la Ley General de derechos de las personas con discapacidad y de su inclusión social, arts. 53 y 54 .

22. Real Decreto Legislativo 1/2013, de 29 de noviembre, por el que se aprueba el Texto Refundido de la Ley General de derechos de las personas con discapacidad y de su inclusión social, arts. $2,3.64$ y ss. 
En cuanto al derecho al voto secreto de las personas ciegas está previsto en el Real Decreto 1612/2007, por el que se regula un procedimiento de voto accesible. La persona deberá comunicar con carácter previo su voluntad de utilizar el procedimiento de voto accesible (se habilita para ello un teléfono gratuito por parte del Ministerio del Interior). De esta forma, en la mesa electoral encontrará toda la documentación en braille para el ejercicio de su derecho.

\subsection{Auto del Tribunal Constitucional relativo al derecho de voto de las personas con discapacidad}

El Tribunal Constitucional (TC) es el intérprete supremo de la Constitución, y entre otras funciones conoce los recursos de amparo que son la vía de protección frente a las vulneraciones de los derechos y libertades fundamentales, entre los que se encuentra en su artículo 23, el derecho de voto:

Los ciudadanos tienen el derecho a participar en los asuntos públicos, directamente o por medio de representantes, libremente elegidos en elecciones periódicas por sufragio universal.

Y sobre este derecho, con relación a las personas con discapacidad, el TC ha tenido oportunidad de pronunciarse, estimando que, la limitación existente en la LOREG del derecho al voto es perfectamente constitucional y no vulnera el artículo 29 de la CDPD.

\subsubsection{Antecedentes}

En diciembre de 2013, Doña MMCV (la demandante) interpuso demanda de incapacitación frente a su hija Doña MGC. La demandante solicitó la prórroga de la patria potestad de su hija por estar próxima a la mayoría de edad; y que se le conservaran sus derechos personalísimos, en especial, su derecho al voto. El 2 de septiembre de 2014, el Juzgado de Primera Instancia declaró la incapacitación parcial de Doña MGC, negándole el derecho al voto con base en su desconocimiento de aspectos básicos y fundamentales del sistema político y del sistema electoral, y así como por su supuesta influenciabilidad. Esta decisión judicial de limitación del derecho de voto fue recurrida ante todas las instancias previstas legalmente, siendo todas desestimatorias, incluida la del Tribunal Supremo (TS) ante el que se interpuso, en abril de 2015, recurso de casación.

En su sentencia, el TS, estimó que dicha privación era legalmente compatible con lo establecido en la CDPD: 
la decisión de privación del derecho de sufragio activo es por tanto legalmente posible y compatible con la Convención de Nueva York, sin perjuicio de que para la eventual adopción de tal medida sea preciso examinar de forma concreta y particularizada las circunstancias e intereses concurrentes, evitando todo automatismo, incompatible con los derechos fundamentales en juego, para calibrar la necesidad de una medida dirigida a proteger los intereses del incapaz y el propio interés general de que la participación electoral se realice de forma libre y con un nivel de conocimiento minimo respecto del derecho al votar y de la decisión adoptada, como advierte la sentencia recurrida ${ }^{23}$.

El 28 de abril de 2016, la demandante interpuso recurso de amparo contra la sentencia del TS ante el Tribunal Constitucional. La demandante alegó la vulneración del artículo 23 de la Constitución Española en relación con el artículo 10 apartado 2 (interpretación de los derechos fundamentales), y en relación con el artículo 14 (derecho a la igualdad). El 23 de junio de 2016 la demanda fue inadmitida a trámite por el TC «dada la manifiesta inexistencia de violación de un derecho fundamental tutelable en amparo ${ }^{24}$ »

El Ministerio Fiscal, mediante escrito de 21 de julio, interpuso recurso de súplica frente a la inadmisión del TC al entender que no era plenamente descartable la existencia de una apariencia de lesión constitucional de los derechos fundamentales consagrados en los artículos 14 y 23 de la Constitución, en los términos denunciados por los recurrentes. Para el Fiscal ante el TC, la lesión podría tener su origen en la propia previsión normativa del artículo 3 de la LOREG, o en la interpretación que del mismo se está haciendo, por lo que entiende que no puede descartarse la lesión del artículo 23.1 de la CE por parte de los órganos judiciales, lo que infiere $\mathrm{de}^{25}$ :

a) No parece que se haya valorado adecuadamente la manifestación de la interesada de su voluntad de seguir votando.

b) No se ha practicado prueba alguna sobre el perjuicio que el derecho al

23. Tribunal Supremo, Sala de lo Civil, Sentencia No 181/2016, 17 de marzo 2016, fundamento de derecho segundo.

24. Tribunal Constitucional, Sala Segunda, Sección Tercera, No de recurso 2415-2016- C, Providencia 23 de junio 2016.

25. Tribuna Constitucional, Sala Segunda, Sección Tercera, No de recurso 2415-2016, Auto 196/2016, de 28 de noviembre de 2016, antecedentes, punto 5. 
voto pudiera causar a la interesada, o sobre que su capacidad de decisión estuviera perturbada.

c) El nivel de conocimientos políticos o la supuesta influenciabilidad no parecen argumentos suficientes para privar del derecho al voto por razón de discapacidad, en primer lugar, porque implica exigir un plus que no se exige a nadie más, y, en segundo lugar, porque el concepto de influenciabilidad es difícilmente objetivable.

Este recurso fue inadmitido por el TC mediante Auto 196/2016 de 28 de noviembre de $2016^{26}$.

\subsubsection{Auto 196/2016, de 28 de noviembre de 2016 del Tribunal Constitucional}

El TC, en un escueto auto, desestima la admisión del recurso de súplica interpuesto por el Ministerio Fiscal con los siguientes razonamientos ${ }^{27}$ :

a) El derecho al voto reconocido en el artículo 23.1 de la Constitución a todos los ciudadanos es de configuración legal, es decir, que su concreción la debe establecer el legislador sin menoscabo de su contenido esencial. La LOREG condicionan el ejercicio a un conjunto de circunstancias como la edad, la nacionalidad y entre las que está también la privación judicial, y esta privación singularizada no es contraria al sufragio universal, máxime cuando dicha privación está revestida de garantía judicial y no es automática sino individualizada.

b) La interpretación del artículo 23 CE conforme con el artículo 29 de la CDPD y con relación al artículo 3.1 de la LOREG, permite dicha privación.

c) No existe discriminación por razón de discapacidad, porque dicha restricción no afecta a todas las personas con discapacidad como colectivo y por razón de cualquier discapacidad. En este sentido las limitaciones son solo con respecto a quién se decida, por sentencia, tras un proceso que cuenta con las debidas garantías de defensa y prueba, y por razón de «su capacidad intelectiva y volitiva respecto al ejercicio del derecho de voto». Precisamente el artículo 29 de la CDPD así lo corrobora pues su finalidad

26. Tribunal Constitucional, Sala Segunda, Sección Tercera, $N^{\circ}$ de recurso 2415-2016, Auto 196/2016, de 28 de noviembre de 2016.

27. Tribunal Constitucional, Sala Segunda, Sección Tercera, $N^{\circ}$ de recurso 2415-2016, Auto 196/2016, de 28 de noviembre de 2016, fundamentos jurídicos. 
«es la de garantizar el efectivo ejercicio del voto que sea fiel reflejo de la libre voluntad de la persona con discapacidad y no, por el contrario, la mera introducción de la papeleta electoral en la urna».

d) Las privaciones del derecho en las diferentes sentencias previas del caso MGC no son arbitrarias, ni irracionales ni contienen error manifiesto, sino que cumplen con las exigencias de motivación reforzada exigible a una privación de derechos.

e) El pronunciamiento cuestionado no depende de la posesión por la persona de cierto nivel de conocimientos o instrucción, que no se exige al resto de los ciudadanos no sometidos a un proceso de incapacitación. Estos conocimientos son un dato que, junto a otros, pueden utilizarse para el juicio de aptitud de entender y querer. Por otra parte, la pericial médico-psiquiátrica tiene especial relevancia, tanto para la valoración antes mencionada como para determinar la influenciabilidad por terceros, que también fue constada por el juez. Es por tanto una cuestión ligada al grado de desarrollo de las facultades mentales de la misma.

\subsubsection{Voto particular del Auto 196/2016 del Tribunal Constitucional}

La resolución mediante el mencionado auto no es pacífica, pues cuenta con un voto particular de la Magistrada Dra. Adela Asúa, en el que manifiesta su discrepancia al entender que debía haberse admitido el recurso de súplica promovido por el Fiscal. Entre otros aspectos, el voto particular afirma que ${ }^{28}$ :

a) El recurso de amparo sí tiene relevancia constitucional ya que no existe doctrina del TC en este ámbito cuando los titulares del derecho son personas con discapacidad, lo que indica la trascendencia del asunto al afectar a un colectivo importante que está en situación de vulnerabilidad por razón de su discapacidad. Que además, esta trascendencia es aún mayor al haber ratificado España la Convención Internacional sobre los Derechos de las Personas con Discapacidad, y que, por si esto fuera poco, el Comité sobre los Derechos de las Personas con Discapacidad, en las observaciones finales aprobadas el 23 de septiembre de 2011 en relación con el informe presentado por España, manifestó su preocupación por el hecho de que se pudiera restringir el derecho al voto de las personas con discapacidad

28. Tribunal Constitucional, Sala Segunda, Sección Tercera, No de recurso 2415-2016, Auto 196/2016, de 28 de noviembre de 2016, Voto particular. 
intelectual o psicosocial, si la persona interesada hubiese sido privada de su capacidad jurídica o hubiese sido internada en una institución, al tiempo que pidió expresamente al Estado español que modificara el art.3 LOREG, con el objeto de que se permitiera que todas las personas con discapacidad tuvieran derecho a votar. Y, además, conforme al art. 10.2 $\mathrm{CE}$, debe interpretarse el art. 23.1 CE de conformidad con las previsiones de la citada Convención.

b) No cabe concluir por parte del TC la manifiesta inexistencia de violación de derecho tutelable en amparo porque no cabe rechazar de forma rotunda que el art. 3 LOREG permita la lesión de los arts. 14 y 23.1 CE que se invocaba en la demanda de amparo.

c) La Constitución establece la obligación de facilitar el ejercicio de los derechos fundamentales, lo que constituye un imperativo indeclinable para los poderes públicos, y que cobra particular importancia en el caso del derecho de sufragio y de los demás derechos de participación política.

d) Que la configuración legal de los derechos reconocidos en la Constitución no puede implicar que dichos preceptos son constitucionales por su propia regulación como pretende el auto, porque de ser así se llega al inadmisible corolario de que ninguna de las leyes que desarrollara derechos fundamentales podría ser inconstitucional en la medida en que se trate de derechos de configuración legal, por ello, debe respetarse el contenido esencial del mismo, y precisamente, sobre el contenido esencial del artículo 23 el auto no hace mención alguna.

e) La restricción del artículo 3 de la LOREG al derecho de sufragio es por razón de discapacidad, y, el art. 29 de la Convención conmina a que deben ofrecerse todos los medios precisos para que las personas con discapacidad puedan participar en la vida pública en pie de igualdad con los demás ciudadanos. Y aunque el art. 29 de la Convención no es canon de constitucionalidad, sí es elemento interpretativo del art. 23.1 CE y del alcance que se deba otorgar al derecho que se reconoce en el mismo.

f) El artículo 23.1 CE no incluye las razones para privar del derecho de voto a una persona con discapacidad, tampoco incluye explicación alguna ni estándares de actuación de los órganos judiciales con el artículo 3.1 b) LOREG, de manera que la privación del derecho de voto se remite al libre criterio judicial, en un procedimiento que, ni por un momento, se orienta a remover los obstáculos y facilitar los medios necesarios para que las personas con discapacidad, independientemente de la misma, tuvieran derecho a votar 
y a participar en la vida pública en igualdad de condiciones que los demás ciudadanos.

g) Estima que el TC hace dejación de funciones al remitirse a la reciente jurisprudencia del TS para afirmar la compatibilidad del artículo 29 de la CDPD y del artículo 3 de la LOREG, pues, precisamente, lo que se enjuiciaba entre otras resoluciones era dicha sentencia a la que el TC se remite, es más, ni siquiera ha atisbado a apuntar el contenido esencial del derecho al voto.

h) El objeto del amparo es la vulneración de un derecho sustantivo, el del art. 23.1 CE en relación con el art. 14 CE (que suelen encontrarse estrechamente unidos). Estima que hubiera sido necesario que se realizara una ponderación, un juicio de proporcionalidad, que permitiera determinar que

la limitación del derecho fundamental era apta para lograr un fin constitucional, que fuera necesaria, en el sentido de que no existiera una medida menos gravosa para conseguir ese fin, $y$, por último, que superara el juicio de proporcionalidad en sentido estricto, determinando que los beneficios de la medida fueran mayores que los perjuicios que ha ocasionado.

i) Con relación a la "influenciabilidad", debe decirse que transita de constatada en primera instancia a hipotética en la sentencia de apelación, y que, prescindiendo de la voluntad manifestada por la afectada de continuar ejerciendo su derecho al voto, es privada del mismo. Por otra parte, y siguiendo al Fiscal, el artículo 23.1 no condiciona el derecho al voto a la posesión de un conjunto de conocimientos y capacidades, sino a la condición de ciudadano, y que imponer a las personas con discapacidad a un examen de conocimientos políticos es imponer una barrera y un plus frente a los demás ciudadanos, lejos de ser una forma de facilitar y apoyar su participación.

j) Concluye esperando que los demandantes sigan luchando en instancias internacionales para el reconocimiento del derecho de participación política de su hija ${ }^{29}$.

29. Actualmente se ha presentado demanda ante el Tribunal Europeo de Derechos Humanos, la elaboración de la misma ha sido posible gracias la colaboración desinteresada de un grupo de juristas entre los que me encuentro y que está constituido por los Dres. Lourdes González-Laganá (Abogada), Cristina Campayo Soriano, Almudena Pérez Vizán y Nestor Pelechá Aigües. 


\subsection{Vulneraciones del derecho de participación política}

El siguiente apartado hace un análisis de la realidad fáctica de este derecho.

\subsubsection{La denegación del derecho al voto como realidad creciente en España}

De acuerdo con los datos facilitados por la Junta Electoral Central ${ }^{30}$, se observa que la denegación del derecho al voto es una realidad creciente en España.

\begin{tabular}{|l|c|c|c|c|c|r|}
\cline { 2 - 7 } \multicolumn{1}{|c|}{} & \multicolumn{1}{l|}{ Elecciones generales } \\
\hline Años & 2000 & 2004 & 2008 & 2011 & 2015 & 2016 \\
\hline $\begin{array}{l}\text { Personas privadas } \\
\text { del derecho del voto }\end{array}$ & 12.709 & 31.262 & 55.949 & 79.398 & 96.748 & 98.488 \\
\hline
\end{tabular}

Si atendemos a su distribución por sexos, encontramos que afecta en mayor proporción a mujeres.

\begin{tabular}{|c|c|c|c|}
\hline \multirow[b]{2}{*}{ Años } & \multicolumn{3}{|c|}{ Personas privadas del derecho al voto } \\
\hline & Total & Mujeres & Hombres \\
\hline 2016 & 98.488 & 51.901 & 46.587 \\
\hline 2015 & 96.748 & 51.033 & 45.715 \\
\hline 2011 & 79.398 & 42.475 & 36.923 \\
\hline
\end{tabular}

\subsubsection{Otras formas de denegación de la participación política}

Además de la denegación del derecho al voto, cada vez que hay elecciones se producen restricciones y negativas a la participación en el proceso electoral en condiciones de igualdad y no discriminación.

30. La Junta Electoral Central es el órgano superior de la Administración Electoral. Tiene carácter permanente y sede en el Congreso de los Diputados en Madrid. Tiene, entre otras competencias cursar instrucciones de obligado cumplimiento a las Juntas Electorales Provinciales y, en su caso, de Comunidad Autónoma; Resolver con carácter vinculante las consultas que le eleven las Juntas Provinciales y, en su caso, las de la Comunidad Autónoma; Unificar los criterios interpretativos de las Juntas Electorales Provinciales y, en su caso, de Comunidad Autónoma en la aplicación de la normativa electoral. http://www.juntaelectoralcentral.es/cs/jec/inicio 
No hay datos cuantitativos de este tipo de vulneraciones, pero una muestra significativa de la misma aparece reflejada tanto en prensa como en los informes anuales del CERMI ${ }^{31}$ sobre Derechos Humanos y Discapacidad. Estos informes contienen de forma sistemática denuncias contra la denegación del derecho a participar en las mesas electorales por razón de discapacidad, y la denegación de mecanismos de accesibilidad o ajustes razonables. El informe de 2008, denuncia que una persona con discapacidad visual no pudo participar en una mesa electoral porque la Junta Electoral le negó un listado con un mayor tamaño de la letra, y dos personas sordas fueron expulsadas de una mesa electoral por su discapacidad ${ }^{32}$. En 2011, le prohibieron a una persona ciega ser presidenta de una mesa electoral por falta de desarrollo normativo al respecto ${ }^{33}$. Posteriormente, se produjo dicho desarrollo normativo ${ }^{34}$ tendiente a garantizar esta participación, pero fue insuficiente, así, en 2012, la Confederación Española de Familias de Personas Sordas denunció que el Reglamento de condiciones básicas de accesibilidad a los procesos electorales, no regulaba los medios de apoyo a la comunicación oral para personas sordas que son usuarias de prótesis auditivas y que comunican en lengua oral (bucles magnéticos, emisoras FM) con lo que se les impide cumplir con su deber ciudadano de formar parte de una mesa electoral, en igualdad de condiciones que los demás ${ }^{35}$. No solo es insuficiente, sino que se siguen sucediendo vulneraciones, de hecho, en 2014 la Junta Electoral Central le negó la participación a una persona con discapacidad en la mesa electoral, y en vez de proceder a facilitar los ajustes razonables que establece la norma le eximió de la obligación de participar en contra de la voluntad del ciudadano ${ }^{36}$. En 2016 una joven con parálisis cerebral acudió a la cita de su nombramiento como vocal primera y le fue denegada la participación

31. El CERMI es el comité español de representantes de personas con discapacidad, y además de ser la entidad más representativa de la discapacidad en España, fue designada por el estado español para ser el mecanismo independiente para el seguimiento y aplicación de la Convención Internacional sobre los derechos de las personas con discapacidad. Con carácter anual elabora un informe de derechos humanos y discapacidad en el que refleja, entre otros, las principales vulneraciones a los derechos contenidos en la CDPD.

32. CERMI (2009), pp. 44-45.

33. CERMI (2012), pp. 190-110.

34. Real Decreto 422/2011, de 25 de marzo, por el que se aprueba el Reglamento sobre las condiciones básicas para la participación de las personas con discapacidad en la vida política y en los procesos electorales.

35. CERMI (2013), pp. 87-88.

36. CERMI (2015), p. 124. 
"porque otros compañeros de mesa consideraron que no estaba preparada y que su discapacidad le impedía ejercer como vocal (...) antes de que se sentara, la segunda vocal le dijo que se marchara y en su puesto se colocó al suplente". Esta situación ha sido reclamada ante la Junta Electoral Central por cuanto la segunda vocal no tenía ningún derecho a echarla ${ }^{37}$.

Por otra parte, es de reseñar que situaciones de facto similares encuentran soluciones de derecho diferente, lo que es una clara muestra de la incertidumbre jurídica en el derecho de participación política. En este sentido en las elecciones autonómicas y locales de 2015, dos personas con discapacidad visual fueron convocadas a formar parte de la mesa electoral, una en Pamplona y otra en Salamanca. Ambas plantearon sus necesidades para poder ejercer este derecho en condiciones de igualdad y no discriminación, y las respuestas que encontraron son divergentes: en Salamanca su Junta Electoral adoptó un acuerdo favorable para que se solicitase de la Subdelegación del Gobierno ${ }^{38}$ la provisión de los medios adecuados, petición que fue atendida por el Ministerio del Interior y que resolvió que se facilitaría un asistente personal retribuido con cargo al presupuesto electoral, y por su parte la de Pamplona desestimó su participación ${ }^{39}$.

También se producen otras denuncias por la falta de accesibilidad ${ }^{40}$ :

a) Los itinerarios de acceso no son totalmente accesibles (aceras exteriores con pavimento resbaladizo, con desniveles, existencia de escalones en la entrada insalvables a menos que se acometan obras estructurales, etc....).

b) Si bien cuentan con ascensores o salva escaleras, estos elementos no estaban en funcionamiento el día de celebración de las elecciones.

c) Si bien cuentan con rampas fijas de acceso, estas han sido construidas con pendientes excesivas o sin barandilla.

d) Se han utilizado rampas móviles inadecuadas.

e) Si bien cuentan con una entrada alternativa accesible, esta no estaba abierta o disponible el día de celebración de las elecciones, o no estaba bien señalizada.

37. La Voz de Almería, "Una joven con parálisis fue vetada como vocal electoral”, 30/06/2016.

38. Se integra dentro de la Administración Periférica del Estado, es la encargada de ejercer la actividad del Estado en el ámbito provincial, correspondiendo al Delegado del Gobierno la dirección de la misma en el ámbito autonómico y su coordinación con la Administración de la propia comunidad autónoma

http://www.seat.mpr.gob.es/portal/delegaciones_gobierno/administracion-periferica.html

39. CERMI (2016), pp. 154-155.

40. DIRECCIÓN GENERAL DE POLÍTICA INTERIOR (2012), pp. 27 y ss. 
f) La altura a la que se encuentran, dentro de las cabinas de votación, las papeletas de las diferentes candidaturas.

g) Las listas censales están a una altura que no son accesibles para a las personas usuarias de sillas de ruedas.

Otra cuestión es que el derecho al voto secreto para las personas con discapacidad solo está garantizado en las elecciones nacionales y autonómicas, no estándolo aún las municipales ${ }^{41}$.

Esta reiterada situación de discriminación llevó al CERMI a elevar una petición a la Junta Electoral Central (JEC) solicitando una unificación de criterios interpretativos que garantizara el derecho de sufragio de las personas con discapacidad y su participación en los procesos electorales ${ }^{42}$.

En su respuesta, la JEC parte de la existencia de obstáculos innegables que dificultan las facultades que integran el derecho al sufragio, y recuerda que su actuación se enmarca en el principio de igualdad, y resalta que ${ }^{43}$ :

a) La cuestión de la accesibilidad de los espacios y lugares donde se celebran actos de campaña corresponde a las Juntas Electorales de Zona, quienes ostentan la facultad indelegable y exclusiva de exigir a los Ayuntamientos el adecuado cumplimiento de las obligaciones en materia de accesibilidad, y, por tanto, pueden acordar modificaciones respecto de los lugares públicos que los Ayuntamientos hubieran reservado.

b) Con relación a la accesibilidad de las sedes de los colegios electorales, corresponde a las delegaciones provinciales de la Oficina del Censo Electoral determinar los locales a propuesta de los Ayuntamientos. Las Juntas Electorales Provinciales deben velar por la accesibilidad, cabiendo ante ellas recurso caso de que la propuesta no lo fuera.

c) En cuanto a la participación de las personas con discapacidad en las mesas electorales, menciona los diferentes pronunciamientos de la Junta Electoral Central sobre el apoyo de intérpretes de lengua de signos, y se remite a la normativa actual que prevé que debe tramitarse la petición ante la Junta Electoral de Zona, y esta a su vez ante la Subdelegación del Gobierno. Sin embargo, en el caso de las personas con discapacidad visual, recuerda que,

41. CERMI (2012), pp. 190-110.

42. CERMI (2017), p. 70.

43. CERMI (2017), p. 70. 
si bien no existe normativa, han elevado una propuesta de modificación normativa para que sea más favorable para las personas con discapacidad visual, pero en tanto esta no se produzca no se puede garantizar su participación.

\section{Conclusiones}

Del análisis realizado se puede concluir que la realidad fáctica, legal y jurisprudencial española con relación al derecho de participación política está marcada tanto por la falta de adaptación normativa, como por la aplicación insuficiente de la normativa en vigor, con el efecto de vulnerar tanto la titularidad del derecho como su ejercicio.

Sobre las restricciones en la participación en los procesos electorales (limitaciones al ejercicio)

La realidad muestra que, pese a la normativa en vigor, se producen vulneraciones en el derecho de participación política. Un claro ejemplo de interpretación restrictiva e insuficiente es el dado por la Junta Electoral Central frente a las quejas planteadas por el CERMI (vid. apartado 3.5.2).

El mismo, pese a los incumplimientos que conoce, hace una remisión acrítica a la normativa, además no dirime responsabilidad alguna en una estructura orgánica de la que ostenta la supremacía jerárquica y, por otro lado, y en relación con las posibles adaptaciones necesarias para la participación de las personas con discapacidad en las mesas electorales, esgrime que solo está regulada la de las personas con discapacidad auditiva que sean usuarias de la lengua de signos, pues es lo único establecido por el Real Decreto 422/2011, de 25 de marzo, por el que se aprueba el Reglamento sobre las condiciones básicas para la participación de las personas con discapacidad en la vida política y en los procesos electorales

Frente a esta interpretación restrictiva, basta poner en evidencia lo establecido por la Convención en su artículo 29, o en la propia Ley General de los Derechos de las personas con discapacidad que, desde su supremacía jurídica frente a un reglamento, prevé la obligación de proveer adaptaciones y ajustes razonables a las personas con discapacidad en su derecho de participación política. La JEC no puede esgrimir que falta regulación, pues la ley, dada la especificidad de los ajustes, lo que hace es establecer su obligatoriedad, quedando para cada caso concreto la determinación de una solución adecuada, no hacerlo es conforme a todo lo visto, discriminatorio. 
Las previsiones de normativas que competen a los partidos políticos y sus campañas $^{44}$ son profundamente vagas y posibilistas, de hecho no establece obligación alguna, sino que lo ciñe al jurídico indeterminado de lo posible. Por tanto, no se está garantizando en condiciones de igualdad y no discriminación el acceso a la información que permite, precisamente, el proceso de adopción de decisión.

Y, por último, el Real Decreto 1612/2007, por el que se regula un procedimiento de voto accesible, aún no aplica a las elecciones municipales en las que el voto secreto aún no está reconocido.

\section{Sobre las restricciones en el derecho al voto (restricciones a la titularidad)}

La restricción del derecho al voto en España es contraria a la Constitución en su artículo 23 de acuerdo con la interpretación que debe darse de conformidad con el art. 10.2 CE en relación con el artículo 29 y 12 de la CDPD.

Una sociedad democrática se basa en la igualdad y la libertad bajo un axioma claro: un ciudadano un voto, de forma que las decisiones colectivas -y en este caso, los resultados electorales- respondan de la forma más auténtica posible a la voluntad popular. Conforme a lo ya expuesto, el derecho de voto no está ligado a la posesión de un determinado nivel de conocimientos o competencias, sino a la condición de ciudadano, pues es este el título para participar en las decisiones acerca del devenir de la comunidad política. Lo que se exige, aunque el TC lo haya obviado, es libertad e igualdad y no discriminación.

- Libertad. La CDPD y la CE no definen ni establecen restricciones ni limitaciones, solo exigen la salvaguarda de la libertad, que de conformidad con el artículo 9.2 de la CE exigirá mayores medidas en el caso de las personas con discapacidad, por tanto, no hay colisión entre las mismas y no pueden ser vulneradas por normativa de rango inferior. Siendo la máxima garantía la libertad no su privación.

La protección de la libertad en el sufragio es una medida que debe estar garantizada a todos los ciudadanos. Precisamente, con relación a la carencia de libertad, uno de los argumentos que se esgrimen es la posibilidad de influencia indebida. En este sentido, medir la libertad individual no es posible, es más, la garantía y defensa de la libertad corresponde al Estado no al sujeto de

44. Real Decreto 422/2011, de 25 de marzo, por el que se aprueba el Reglamento sobre las condiciones básicas para la participación de las personas con discapacidad en la vida política y en los procesos electorales. 
derecho, y lo que no puede hacer el Estado es defender limitando, es decir, si el riesgo es que el individuo con discapacidad pueda recibir una influencia indebida, el eje de actuación estatal no es limitar ese derecho, sino darle mayor garantía con un sistema electoral libre y accesible para las personas con discapacidad con los apoyos que sean adecuados. Esta radicalidad de planteamiento corresponde al modelo de derechos humanos que aporta la CDPD.

Por tanto, el único requisito, tanto de la Convención como de la Constitución española es la libertad, no la capacidad o los conocimientos de la persona. Es decir, el derecho va ligado a la condición de ciudadano.

- Igualdad y no discriminación. El derecho al sufragio, de acuerdo con su contenido esencial, exige ser garantizado en condiciones de igualdad y no discriminación. Desde esta afirmación del Comité CDPD, no es posible realizar examen alguno a un grupo diferenciado y diferenciable para validar su aptitud, pues va en contra del sentido abstracto de democracia. De nuevo, la clave como en la libertad, está en los mecanismos de garantía de su ejercicio en condiciones de igualdad y no discriminación. Otro debate diferente, al que no procede entrar, sería si debería examinarse a toda la población para determinar su capacidad de elección libre. Entrar a limitar mediante la evaluación ya sea de la capacidad, de la calidad o de la libertad individual son quimeras imposibles. Un voto es una elección y es individual y personal, de hecho, la pluralidad política es expresión de la variabilidad humana en cuanto a elecciones, y del respeto a dichas elecciones personales. Cuando alguien vota diferente a nuestras creencias no se entra a medir la calidad de su voto, pero cuando ese voto, cuyo contenido se desconoce, lo ejerce una persona con discapacidad se cuestiona su elección, su libertad, su calidad.

- Proporcionalidad. Los derechos nos son absolutos, la colisión entre ellos es tan posible y real como la necesidad de definir un sistema que ayude a determinar, en situaciones de conflicto, la prevalencia de uno sobre otro. La proporcionalidad implica buscar un equilibrio justo en la contraposición de intereses, especialmente si estamos ante un interés general frente a un derecho individual. El Comité CDPD destaca que esta privación no es proporcionada por las siguientes razones ${ }^{45}$ :

45. COMITÉ SObRE LOS DERECHOS DE LAS PERSONAS CON DiSCAPACIDAD (2011, a) par. 5.6-5.10. 
a) Las evaluaciones de la capacidad constituyen una discriminación por motivos de discapacidad.

La legitimidad de la privación del derecho para proteger la integridad del sistema político es cuestionable, ya que no compete al Estado determinar qué es una opinión política válida. La imposibilidad o dificultad de emitir un voto "con conocimiento de causa" o "racional" no es, en modo alguno, una característica específica y exclusiva de las personas con discapacidad. Por tanto, si hay personas con y sin discapacidad que no pueden votar con conocimiento de causa, no puede sostenerse que solo estas últimas deban someterse a una evaluación de la capacidad.

b) Provocan inevitablemente que se prive de derechos a personas capaces. No es posible definir una distinción precisa entre las personas con y sin capacidad para votar. Por ello, si se mantiene este esquema, siempre habrá casos en que las evaluaciones de la incapacidad den lugar a la privación del derecho de voto de algunos electores capaces, independientemente de su discapacidad.

c) En la práctica, su aplicación conlleva la privación del derecho de voto de un gran número de personas con discapacidad.

Es creciente el número de personas, que, conforme a este sistema, quedaría privado del derecho de participación política.

\section{Síntesis}

La Convención sobre los derechos de las personas con discapacidad reconoce desde la igualdad, la no discriminación y la autonomía los derechos humanos de las personas con discapacidad, en su titularidad y ejercicio, entre los que se encuentra el derecho de participación política. Por tanto, debe modificarse el artículo 3.1 de LOREG eliminado la actual restricción, y debe habilitarse los apoyos y garantías que sean necesarias para su ejercicio. Y, de la misma manera, debe garantizarse el derecho de participación en todo el proceso electoral. Sin estas medidas, España está incumpliendo la Convención.

\section{Refrencias bibliográficas}

Cermi (2009), Derechos Humanos y Discapacidad, Informe de España 2008 (Madrid, Cinca). 
Cermi (2012), Derechos Humanos y Discapacidad, Informe de España 2011 (Madrid, Cinca).

Cermi (2013), Derechos Humanos y Discapacidad, Informe de España 2012 (Madrid, Cinca).

Cermi (2015), Derechos Humanos y Discapacidad, Informe de España 2014 (Madrid, Cinca).

Cermi (2016), Derechos Humanos y Discapacidad, Informe de España 2015 (Madrid, Cinca).

Cermi (2017), Derechos Humanos y Discapacidad, Informe de España 2016 (Madrid, Cinca).

COMITÉ SOBRE LOS DERECHOS DE LAS PERSONAS CON DISCAPACIDAD (2011, a), Comunicación 4/2011, UN Doc. CRPD/C/10/D/4/2011, 16 de octubre de 2011.

COMITÉ SOBRE LOS DERECHOS DE LAS PERSONAS CON DISCAPACIDAD (2011, b), Examen de los informes presentados por los Estados partes en virtud del artículo 35 de la Convención, UN Doc. CRPD/C/ESP/CO/1, 19 de Octubre de 2011.

CommitTeE ON THE RIgHTS OF PERSONS with DisAbilities (2014, a), General comment $\mathrm{N}^{\circ}$ 1, Article 12: Legal Capacity (Adopted 31 March 2014), UN Doc., CRPD/C/GC/1.

COMmitTEe ON THE RIGHTS OF PERSONS With DisAbilities $(2014, \mathrm{~b})$, General comment No 2, Article 9: Accessibility (Adopted 22 May 2014), Doc. UN CRPD/C/GC/2.

Committee ON THE RightS OF PERSONS WITH DisAbiLITIES (2016, a), General comment N $^{\circ}$ 3, Article 6: Women and girls with disabilities (Adopted 26 August 2016), UN Doc., CRPD/C/GC/3.

COMmitTEe ON THE RIGHTS OF PERSONS With DisAbilities (2016, b), General comment $\mathrm{N}^{\circ}$ 4, Article 24: Right to inclusive education (Adopted 26 August 2016), UN. Doc. CRPD/C/GC/4.

CommitTeE ON the RIgHTS OF PERSONS with Disabilities (2014, c), General comment $\mathrm{N}^{\circ}$ 5, Article 19: Right to independent living, (Adopted 29 August 2016), UN Doc. CRPD/C/18/1.

Dirección General de Política Interior (2012), Informe de evaluación sobre accesibilidad y procesos electorales (Madrid, Ministerio del Interior).

Fiscalía General del Estado (2010), Instrucción No 3/2010, Sobre la necesaria fundamentación individualizada de las medidas de protección o apoyo en los procedimientos sobre determinación de la capacidad de las personas.

OMS y BANCO Mundial (2011), Informe mundial sobre la discapacidad, Ginebra.

Asamblea General, Reforma de las Naciones Unidas: medidas y propuestas, Doc. A/66/860, 26 de junio de 2012. 


\section{Jurisprudencia citada}

Tribunal Supremo, Sala de lo Civil, Sentencia No 181/2016, 17 de marzo 2016.

Tribunal Constitucional, Sala Segunda, Sección Tercera, $N^{\circ}$ de recurso 2415-2016C, Providencia 23 de junio 2016.

Tribunal Constitucional, Sala Segunda, Sección Tercera, $N^{\circ}$ de recurso 2415-2016, Auto 196/2016, de 28 de noviembre de 2016. 